\title{
Postpartum Depression and the Affordable Care Act: Recommendations for Social Work Educators
}

\author{
Robert H. Keefe \\ Carol Brownstein-Evans \\ Sandra D. Lane \\ D. Bruce Carter \\ Rebecca S. Rouland Polmanteer
}

\begin{abstract}
The Patient Protection and Affordable Care Act (ACA) mandates ongoing research on postpartum depression; however, very little research has been published in social work journals and in advanced-level textbooks on this topic. This article describes the problem of postpartum depression and argues that social work educators and researchers must pay greater attention to this issue in light of the ACA mandates, so that social workers can provide effective services to postpartum mothers and their children. The Council on Social Work Education's recently published Educational Policy and Accreditation Standards are considered while making curriculum recommendations on postpartum depression for social work educators.
\end{abstract}

Keywords: Patient Protection and Affordable Care Act, maternal and child health, postpartum depression, perinatal mood disorders, social work education

Approximately six million pregnancies occur in the United States each year, and up to 25\% of the mothers develop postpartum depression (Gaynes et al., 2005; Schaar, 2012). Mothers with postpartum depression typically experience sadness; loss of interest in activities; noticeable changes in eating and sleeping patterns; problems in thinking, concentrating, and making decisions; feelings of worthlessness, shame, or guilt; thoughts of harming themselves (Centers for Disease Control [CDC], 2013); and increased need for psychiatric hospitalizations for depression and suicidality (Georgiopoulos, Bryan, Wollan, \& Yawn, 2001; Kennedy, Beck, \& Driscoll, 2002; Lucero, Beckstrand, Callister, \& Sanchez Birkhead, 2012). The symptoms are persistent, eventually affecting not only the mother but her infant, spouse/partner, and extended family as well (Letoruneau, Tramonte, \& Willms, 2013; Ngai \& Ngu, 2015).

Babies born to mothers with postpartum depression often develop numerous longstanding problems including decreased cognitive skills (McGarry, Kim, Sheng, Egger, \& Baksh, 2009), poor attention (Ramchandani, Stein, Evans, O’Connor, \& the ALSPAC Study Team, 2005), and social withdrawal (Boyd, Zayas, \& McKee, 2006). The fathers complain of feeling left out and less satisfied in their relationship with the mother (Mitnick, Heyman, \& Slep, 2009).

Robert H. Keefe, PhD, ACSW, LMSW is associate professor, School of Social Work, University at Buffalo, State University of New York, Buffalo, NY 14260-1050. Carol Brownstein-Evans, PhD, ACSW, LMSW is associate professor, Department of Social Work, Nazareth College, Rochester, NY 14168. Sandra D. Lane, PhD, MPH, MA is Laura J. and L. Douglas Meredith Professor, Public Health and Anthropology, Syracuse, University, Syracuse, NY 13244-1030. D. Bruce Carter, PhD, is associate professor, Department of Psychology and Department of Child \& Family Studies, Syracuse University, Syracuse, NY 13244-1030. Rebecca S. Rouland Polmanteer, LMSW is doctoral candidate, School of Social Work, University at Buffalo, State University of New York, Buffalo, NY 14260-1050. 
Unlike symptoms of major depressive disorder, which manifest within two weeks of the precipitating stressors (American Psychiatric Association, 2013), symptoms of postpartum depression may not become evident until several months after the mother has given birth (Chaudron et al., 2010; Parade, Blankson, Leerkes, Crockenberg, \& Faldowski, 2014). Consequently, practitioners may avoid giving a diagnosis of postpartum depression due to what they perceive as the late onset of symptoms.

Moreover, social work journals provide practitioners with limited guidance on postpartum depression. We searched various social work databases for articles published in social work journals focusing on perinatal mood disorders published between the years 1980 to 2015. The search resulted in 101 published articles of which 80 used the term "postpartum depression" in the title. Of the existing articles, only 26 were published in social work journals. Consequently, although the literature on postpartum depression has grown substantially over the past 35 years, only a limited body of the literature has been published in social work journals. The majority of the research has been published in the fields of nursing, psychology, psychiatry, and medicine. As a result, much of this research has focused on individual-level approaches to treatment such as antidepressant medication, interpersonal and cognitive-behavioral therapy, and relapse-prevention strategies. There is very little research on community-level factors to help social workers address the problem of postpartum depression at all levels of intervention and even less on how social work educators can infuse content on postpartum depression into their courses.

The adoption of the Patient Protection and Affordable Care Act (ACA), Section 2952: Support, Education, and Research for Postpartum Depression mandates ongoing research to better understand the frequency and course of postpartum depression, address differences in treatment needs among racial and ethnic groups, and develop culturally competent evidence-based treatment approaches (U.S. Department of Labor, 2012). Given their direct practice, policy development, and research skills, we argue that social workers are among the most skilled professionals providing services to postpartum mothers and should take the lead in addressing the problem of postpartum depression. The purpose of this article is to bring attention to this problem and offer recommendations to social work educators to better prepare students to meet the needs of new mothers affected by postpartum depression.

\section{The Varying Rates of Postpartum Depression}

Prevalence estimates for postpartum depression vary widely across studies. The discrepancy is due in part to varying definitions of the disorder, different conceptualizations of the postpartum time period, and varying assessment and diagnostic approaches (Banti et al., 2011). Although the rates vary, much of the existing research indicates that up to $25 \%$ of new mothers experience postpartum depression (Gaynes et al., 2005; Schaar, 2012). Additionally, rates of postpartum depression may be higher in diverse or vulnerable groups. While some researchers have found the rates of postpartum depression to be higher in rural areas (Villegas, McKay, Dennis, \& Ross, 2011), others have reported the prevalence to be higher in urban areas (Clare \& Yeh, 2012). Likewise, various researchers have found differences among racial and ethnic groups (Gress-Smith, Luecken, Lemery-Chalfant, \& Howe, 2012; Savitz, Stein, Ye, Kellerman, \& Silverman, 
2011) and the likelihood that the rates for low-income mothers and for mothers of color are higher than estimated (CDC, 2008; Dolbier, et al., 2013; Gress-Smith et al., 2012; Lara et al., 2015).

Some researchers have suggested that mothers of color face more elevated rates of postpartum depression than White mothers because of greater life stressors, including economic factors known to affect postpartum depression. To date, research has concluded that compared to White mothers and mothers from privileged backgrounds, mothers of color have lower incomes (Dagher, McGovern, Dowd, \& Gjerdingen, 2012; Feder et al., 2009; Kozinsky et al., 2012; Lara et al., 2015), lower levels of education (Dagher et al., 2012; Lanes, Kuk, \& Tamim, 2011), higher rates of unemployment (Boyce \& Hickey, 2005; Dagher et al., 2012; Janssen, Heaman, Urquia, O’Campo, \& Thiessen, 2012), greater likelihood of single parenting (Boyce \& Hickey, 2005; Lewin, Mitchell, \& Ronzio, 2013), and worse housing conditions (Cutrona et al., 2005; Jacobs, 2011; Redshaw \& Henderson, 2013). Moreover, mothers of color generally have higher rates of chronic diseases such as diabetes mellitus and hypertension (Kim et al., 2014), are more likely to have inadequate health insurance (Blumenthal \& Collins, 2014), and have poorer access to adequate healthcare (Orr, Reiter, James, \& Orr, 2012) than other mothers. Coupled with higher exposure to community violence (Miller et al., 2012), it is understandable that mothers of color are at increased risk of clinical depression.

A further problem is the preponderance of research has considered primarily White women who are married, well-insured, from middle-class backgrounds, and have access to healthcare. The few studies that have focused on mothers of color concluded their rates of postpartum depression to be higher than among White mothers (CDC, 2008; Surkan, Peterson, Hughes, \& Gottlieb, 2006). Yet, social workers employed in maternal and child health settings looking to advance their skills in working with mothers with postpartum depression from non-White backgrounds have a limited body of social work literature to draw upon.

\section{Working with Mothers who have Postpartum Depression}

Social workers employed in health and mental healthcare settings often face various difficulties in working with mothers living with postpartum depression. Many mothers are reluctant to seek treatment, and those who do are often reticent to disclose their symptoms to health care providers (Abrams \& Curran, 2009; CDC, 2008; Ko, Farr, Dietz, \& Robbins, 2012), particularly women from diverse cultures (Dennis \& Chung-Lee, 2006; Kozhimannil, Trinacty, Busch, Huskamp, \& Adams, 2011). Because many of the symptoms of postpartum depression mimic signs of pregnancy including fatigue, anxiety, and irritability, many providers are hesitant to screen for depression (Seehusen, Baldwin, Runkle, \& Clark, 2005). Due to inconsistent screening procedures, depressed pregnant and postpartum women may go without effective treatment until the depression has advanced, which can result in further health risks including poor adherence to prenatal and postnatal care plans, preterm delivery, and low infant birth weight (Littleton, Bye, Buck, \& Amacker, 2010). 
The American College of Obstetricians and Gynecologists (ACOG, 2006) argues that psychosocial screening and feedback performed at an initial visit and every three months thereafter may reduce the risk for persistent depression and improve birth outcomes. Screenings should include an assessment of obstacles to care, unstable housing, unintended pregnancy, barriers to communication among family members, problems with nutrition, ongoing tobacco and other substance abuse, depression, safety, intimate partner violence, and stress (ACOG, 2006; Dobson \& Dozois, 2008).

The National Association of Perinatal Social Workers (NAPSW, 2009) the largest social work organization that most directly addresses the gap in social work education and practice on postpartum depression, consists of roughly 275 members (L. R. Baker, personal communication, July 8, 2015). The NAPSW provides 10 standards for Perinatal Social Workers Working with Patients Experiencing Post Partum Depression. Each standard includes specific roles for social workers. Most important among the standards are for MSW-prepared social workers to conduct full psychosocial assessments of women during the perinatal period for depression (Standard 2); use standardized screening tools to screen for depressive symptoms (Standard 7); provide resources and referrals for all women in the perinatal period, including culturally and linguistically appropriate support groups and evidence-based counseling services (Standard 5); and provide information on postpartum depression to the woman's partner/spouse and family members (Standard 6). In addition, NAPSW (2009) advocates for social workers to be an integral part of the interdisciplinary health teams providing support and education to medical and support staff and to assist in developing and formulating hospital policies and decisions related to the assessment and treatment of postpartum depression (Standards 9 and 10).

Although there are no federal policies that require screening of new mothers for postpartum depression (Rhodes \& Segre, 2013), 12 states have adopted either state legislation, developed awareness campaigns, or convened tasks forces. States that require screening include New Jersey (Findings, Declarations Relative to Postpartum Depression, 2006), Illinois (Perinatal Mental Health Disorders Prevention and Treatment Act, 2008), and West Virginia (Uniform Maternal Screening Act, 2009). Other states require education about postpartum depression including Texas (Relating to Information Provided to Parents of Newborn Children, 2005), Virginia (Certain Information Required for Maternity Patients, 2003), Minnesota (Postpartum Depression Education and Information, 2015), and Oregon (Relating to Perinatal Mental Health Disorders and Declaring an Emergency, 2011). Washington has passed statewide awareness campaigns, and California, Michigan, and Oregon have postpartum depression awareness months (Rhodes \& Segre, 2013). Finally, Maine, Massachusetts, and Oregon have appointed perinatal depression task forces (Rhodes \& Segre, 2013). The remaining 38 states have yet to pass any type of legislation or develop any campaigns to bring the problem of postpartum depression to the public's awareness.

\section{How social work educators can take the lead in working with mothers with postpartum depression}

Given that postpartum depression affects mothers from all backgrounds, incorporating course content on postpartum depression into each curriculum area would be a significant 
step forward in helping social workers take the lead in addressing this growing problem. The Council on Social Work Education (CSWE, 2015), Competency 2 mandates social workers to engage in diversity and difference in practice. With this in mind, social work educators must include research studies and evidence-based treatment approaches aimed at eliminating health and mental health disparities across all areas of health care. Students need to understand various barriers to care that members from oppressed groups face, as well as the limitations of traditional health and mental health treatment and community services (Ley, Copeland, Flint, White, \& Wexler, 2009). Students need to understand how social location (i.e., the groups to which individuals claim membership based on their sex, socioeconomic class, religion, and sexual orientation) may inhibit people from traditionally oppressed backgrounds from seeking care, particularly when the research on approaches to care is based on mothers from privileged backgrounds. Bringing the focus to postpartum depression specifically, social work students should be prepared to address barriers to services and facilitate mothers' access to child care, transportation, and prenatal appointments that accommodate inflexible work schedules. Social work students should also be prepared to advocate for mothers who will likely experience delays in appointments, particularly for mothers who receive public insurance (U.S. Department of Health and Human Services, Office of the Surgeon General, Substance Abuse and Mental Health Services Administration 1999).

Social work research courses. Competency 4 states, social workers are expected to engage in research-informed practice and practice-informed research (CSWE, 2015). Instructors can help students develop and test interventions with individuals, families, groups, and communities and later evaluate those interventions by using various assessment tools. Program evaluation courses should evaluate services postpartum mothers use including Women, Infants, and Children (WIC) clinics, prenatal care agencies, and pediatric clinics. Additionally, students can be taught how to work with cultural brokers to access communities where they can facilitate focus groups and conduct community-based participatory research to help community agencies evaluate the cultural appropriateness of their services. Finally, students can learn to employ qualitative and quantitative methods to obtain client feedback about the experience of postpartum depression and services received.

Human behavior and the social environment courses. Competency 6 states social workers are to engage with individuals, families, groups, organizations, and communities by applying knowledge of human behavior and the social environment (CSWE, 2015). Among the ways educators can help students develop these skills is by including course content on risk and protective factors of postpartum depression in course units focused on the developmental stages of pregnancy, childbirth, and infancy. Students should study theories of societal oppression and how oppression affects women and children. Students can then investigate which theories best explain the lived experiences of new mothers affected by postpartum depression. Instructors can also include content on family systems theory to gain greater understanding of the effects of postpartum depression on the family.

Social work practice courses. Competency 8 requires social workers to intervene with individuals, families, groups, organizations, and communities (CSWE, 2015). Instructors can develop various case scenarios and encourage students to evaluate practice approaches 
and interventions for working mothers living with postpartum depression. The modules can emphasize relationship-building, engagement, contracting, validation, and resource acquisition. Interventions that highlight supportive counseling and problem-solving, and use strengths-based and women's empowerment approaches applicable across settings are needed. Given the impact of postpartum depression on external systems, curriculum modules on family therapy that address the needs of spouses/partners, children, and extended family members as well as group therapy/counseling course modules that address both psychotherapeutic and mutual-aid group strategies for working with mothers who have postpartum depression are needed. Finally, course modules are needed to teach students how to form coalitions with service providers caring for new mothers. These coalitions will help communities to advocate for new, culturally relevant services that enhance formal and informal support systems. Working with agencies to develop brochures that are easy to read and help mothers and families access appropriate services are also needed.

Social policy courses. Competency 5 requires students to engage in policy practice that advances human rights and social justice (CSWE, 2015). Instructors can provide course content on the ACA with specific focus on Section 2952. Students can trace the development of the ACA while considering other legislation focused on bringing to light the needs of mothers and children including the Sheppard-Towner and Melanie BlockerStokes Acts. Students can also write policy statements in their field agencies on how to better provide services to new mothers with postpartum depression in light of the ACA.

Fieldwork. Educational Policy 2.2 requires field educators to provide students with opportunities to integrate classroom content with practical experience. Field educators can assign students in maternal and child healthcare placements to work with first-time mothers, provide education to the mother's partner/spouse and other family members about the signs and symptoms of postpartum depression, explore the use of informal supports, and make referrals to appropriate community resources. Students' cultural competence can be enhanced by field education experiences and service-learning opportunities that involve working with diverse populations across the lifespan (Ley et al., 2009). Finally, better screening methods should be incorporated into agency practice to include not only use of postpartum depression scales (e.g., Edinburgh Postnatal Depression Scale; Cox, Holden, \& Sagovsky, 1987), but also predictors of postpartum depression that would help prepare students for working with new mothers who may develop postpartum depression. Students should also be instructed in the use of standardized screening instruments and on how to advocate with hospitals for developing written plans that provide specialized social work services related to postpartum depression (NAPSW, 2009). Students can be assigned tasks that investigate strategies for how best to remove barriers to care that postpartum mothers of color face including the lack of culturally appropriate and relevant brochures on postpartum depression. Students can develop in-service discussions on the predictors of postpartum depression and assess the agency's readiness to provide services that are affordable, adequate, and accessible to all mothers. 


\section{Summary and Conclusion}

Despite being an ongoing problem for many years, postpartum depression has only begun to receive public attention within the past two decades. Accounts of new mothers harming their newborn babies have brought additional focus to the rationale for developing new services. Many services, however, are being developed without the input of social workers who, given their training in cultural competence, advocacy, and policy development as well as multi-system interventions, can bring a much-needed perspective to address this problem.

Although the social work profession has contributed to the development of services and policies on maternal and child health, it needs to take a more decisive step forward in addressing postpartum depression. The adoption of the ACA affords an excellent opportunity for social work educators to provide learning opportunities for students to address this significant problem so that new mothers and their children can live healthy and productive lives.

\section{References}

Abrams, L. S., \& Curran, L. (2009). “And you're telling me not to stress?” A grounded theory study of postpartum depression symptoms among low-income mothers.

Psychology of Women Quarterly, 33(3), 351-362. doi: http://dx.doi.org/10.1177/036168430903300309

American College of Obstetricians and Gynecologists. (2006). Committee opinion No. 343: Psychosocial risk factors: Perinatal screening and intervention. Obstetrics and Gynecology, 108(2), 469-477. doi: http://dx.doi.org/10.1097/00006250-200608000$\underline{00046}$

American Psychiatric Association. (2013). Diagnostic and statistical manual of mental disorders (5 $5^{\text {th }}$ ed.). Washington, DC: Author.

Banti, S., Mauri, M., Oppo, A., Borri, C., Rambelli, C., Romancciotti, D., ...Cassano, G. B. (2011). From the third month of pregnancy to 1 year postpartum. Prevalence, incidence, recurrence, and new onset of depression. Results from the perinatal depression-research \& screening unit study. Comprehensive Psychiatry, 52(4), 343351. doi: http://dx.doi.org/10.1016/j.comppsych.2010.08.003

Blumenthal, D., \& Collins, S. R. (2014). Health care coverage under the Affordable Care Act - A progress report. New England Journal of Medicine, 371, 275-281. doi: http://dx.doi.org/10.1056/NEJMhpr1405667

Boyce, P., \& Hickey, A. (2005). Psychosocial risk factors to major depression after childbirth. Social Psychiatry and Psychiatric Epidemiology, 40, 605-612. doi: http://dx.doi.org/10.1007/s00127-005-0931-0

Boyd, R. C., Zayas, L. H., \& McKee, M. D. (2006). Mother-infant interaction, life events and prenatal and postpartum depressive symptoms among urban minority women in primary care. Maternal and Child Health Journal, 10(2), 139-148.

doi: http://dx.doi.org/10.1007/s10995-005-0042-2 
Centers for Disease Control [CDC]. (2008). Prevalence of self-reported postpartum depressive symptoms - 17 states, 2004-2005. Morbidity and Mortality Weekly Report, 57(14), 361-366.

CDC. (2013). Depression among women of reproductive age. Retrieved from http://www.cdc.gov/reproductivehealth/Depression/index.htm

Certain Information Required for Maternity Patients, Code Ann. § 32.1-134.01 (2003).

Chaudron, L. H., Szilagyi, P. G., Tang, W., Anson, E., Talbot, N. L., Wadkins, H. L, ...Wisner, K. L. (2010). Accuracy of depression screening tools for identifying postpartum depression among urban mothers. Pediatrics, 125, e609-e671. doi: http://dx.doi.org/10.1542/peds.2008-3261

Clare, C. A., \& Yeh, J. (2012). Postpartum depression in special populations: A review. Obstetrical and Gynecological Survey, 67(5), 313-323. doi: http://dx.doi.org/10.1097/OGX.0b013e318259cb52

Council on Social Work Education. (2015). Final educational policy. Retrieved from http://cswe.org/File.aspx?id=79793

Cox, J. L., Holden, J. M., \& Sagovsky, R. (1987). Detection of postnatal depression: Development of the 10-item Edinburgh Postnatal Depression Scale. British Journal of Psychiatry, 150, 782-786. doi: http://dx.doi.org/10.1192/bjp.150.6.782

Cutrona, C. E., Russell, D. W., Brown, P. A., Clark, L. A. Hessling, R. M., \& Gardner, K. A. (2005). Neighborhood context, personality, and stressful life events as predictors of depression among African American women. Journal of Abnormal Psychology, 114, 3-15. doi: http://dx.doi.org/10.1037/0021-843X.114.1.3

Dagher, R. K., McGovern, P. M., Dowd, B. E., \& Gjerdingen, D. K. (2012). Postpartum depression and health services expenditures among employed women. Journal of Occupational and Environmental Medicine, 54(2), 210-215. doi: http://dx.doi.org/10.1097/JOM.0b013e31823fdf85

Dennis, C. L., \& Chung-Lee, L. (2006). Postpartum depression help-seeking barriers and maternal treatment preferences: A qualitative systematic review. Birth, 33(4), 323331. doi: http://dx.doi.org/10.1111/j.1523-536X.2006.00130.x

Dobson, K. S., \& Dozois, D. J. A. (2008). Risk factors in depression. Oxford, England: Elsevier/Academic Press.

Dolbier, C. L., Rush, T. E., Sahadeo, L. S., Shaffer, M. L., Thorp, J., \& The Community Child Health Network Investigators. (2013). Relationships of race and socioeconomic status to postpartum depressive symptoms in rural African American and nonHispanic White women. Maternal and Child Health Journal, 17(7), 12771287. doi: http://dx.doi.org/10.1007/s10995-012-1123-7

Feder, A., Alonso, A., Tang, M., Liriano, W., Warner, V., Pilowsky, D., ...Weissman, M. M. (2009). Children of low income depressed mothers: Psychiatric disorders and social adjustment. Depression and Anxiety, 26, 513-520. 
Findings, Declarations Relative to Postpartum Depression, NJ. Stat. Ann. Title 26-Health and Vital Statistics § 26:2-175 (2006).

Gaynes, B. N., Gavin, N., Meltzer-Brody, S., Lohr, K. N., Swinson, T., Gartlehner, G., ... Miller, W. C. (2005). Perinatal depression: Prevalence, screening accuracy, and screening outcomes (Evidence Report/Technology Assessment No. 119. AHRQ Publication No. 05-E006-2). Rockville, MD: Agency for Healthcare Research and Quality.

Georgiopoulos, A. M., Bryan, T. L, Wollan, P., \& Yawn, B. P. (2001). Routine screening for postpartum depression. Journal of Family Practice, 50(2), 117-122.

Gress-Smith, J. L., Luecken, L. J., Lemery-Chalfant, K., \& Howe, R. (2012). Postpartum depression prevalence and impact on infant health, weight, and sleep in low-income and ethnic minority women and infants. Maternal and Child Health Journal, 16(11), 887-893. doi: http://dx.doi.org/10.1007/s10995-011-0812-y

Jacobs, D. C. (2011). Environmental health disparities in housing. American Journal of Public Health, 101(S1), S115-S122. doi: http://dx.doi.org/10.2105/AJPH.20http://dx.doi.org/10.300058

Janssen, P. A., Heaman, M. I., Urquia, M. L., O’Campo, P. J., \& Thiessen, K. R. (2012). Risk factors for postpartum depression among abused and nonabused women. American Journal of Obstetrics and Gynecology, 207(6), 489.e1-489.e8. doi: http://dx.doi.org/10.1016/j.ajog.2012.09.022

Kennedy, H. P., Beck, C. T., \& Driscoll, J. W. (2002). A light in the fog: Caring for women with postpartum depression. Journal of Midwifery \& Women's Health, 47(5), 318-330.

Kim, C., Kim, S. Y., Sappenfield, W., Wilson, H. G., Salihu, H. M., \& Sharma, A. J. (2014). Are gestational diabetes mellitus and preconception diabetes mellitus less common in non-Hispanic Black women than in non-Hispanic White women? Maternal and Child Health Journal, 18(3), 698-706. doi: http://dx.doi.org/10.1007/s10995-013-1295-9

Ko, J. Y., Farr, S. L., Dietz, P. M., \& Robbins, C. L. (2012). Depression and treatment among U. S. pregnant and non-pregnant women of reproductive age, 2005-2009. Journal of Women's Health, 21(8), 830-836. doi: http://dx.doi.org/10.1089/jwh.2011.3466

Kozhimannil, D. B., Trinacty, C. M., Busch, A. D., Huskamp, H. A., \& Adams, A. S. (2011). Racial and ethnic disparities in postpartum depression care among lowincome women. Psychiatric Services, 62, 619-625. doi: http://dx.doi.org/10.1176/ps.62.6.pss6206 0619

Kozinsky, Z., Dudas, R. B., Devosa, I., Csatordai, S., Toth, E., Szabo, D., ...Pal, A. (2012). Can a brief antepartum preventive group intervention help reduce postpartum depressive symptomatology? Psychotherapy and Psychosomatics, 81, 98-107. doi: http://dx.doi.org/10.1159/000330035 
Lanes, A., Kuk, J. L., \& Tamim, H. (2011). Prevalence and characteristics of postpartum depression among Canadian women: A cross-sectional study. BMC Public Health, 11, 302-311. doi: http://dx.doi.org/10.1186/1471-2458-11-302

Lara, M. A., Navarrete, L., Nieto, L., Martin, J. P. B., Navarro, J. L., \& Lara-Tapia, H. (2015). Prevalence and incidence of perinatal depression and depressive symptoms among Mexican women. Journal of Affective Disorders, 175, 18-24. doi: http://dx.doi.org/10.1016/j.jad.2014.12.035

Letoruneau, N. L., Tramonte, L., \& Willms, J. D. (2013). Maternal depression, family functioning and children's longitudinal development. Journal of Pediatric Nursing, 28(3), 223-234. doi: http://dx.doi.org/10.1016/j.pedn.2012.07.014

Lewin, A., Mitchell, S. J., \& Ronzio, C. R. (2013). Developmental differences in parenting behavior: Comparing adolescent, emerging adult, and adult mothers. Merrill-Palmer Quarterly, 59(1), 23-49. doi: http://dx.doi.org/10.1353/mpq.2013.0003

Ley, C. E., Copeland, V. C., Flint, C. S., White, J. S., \& Wexler, S. (2009). Communitybased perinatal depression services for African American women: The Healthy Start model. Social Work in Public Health, 24(6), 568-583. doi: http://dx.doi.org/10.1080/19371910802679622

Littleton, H. L., Bye, K., Buck, K., \& Amacker, A. (2010). Psychosocial stress during pregnancy and perinatal outcomes: A meta-analytic review. Journal of Psychosomatic Obstetrics and Gynecology, 31(4), 219-228. doi: http://dx.doi.org/10.3109/0167482X.20http://dx.doi.org/10.518776

Lucero, N. B., Beckstrand, R. L., Callister, L. C., \& Sanchez Birkhead, A. C. (2012). Prevalence of postpartum depression among Hispanic immigrants. Journal of the Academy of Nurse Practitioners, 1-9. doi: http://dx.doi.org/10.1111/j.17457599.2012.00744.x

McGarry J., Kim, H., Sheng, X., Egger, M., \& Baksh, L. (2009). Postpartum depression and help-seeing behavior. Journal of Midwifery \& Women's Health, 54(1), 50-56. doi: http://dx.doi.org/10.1016/j.jmwh.2008.07.003

Miller, E. M., Levenson, R., Herrera, L., Kurek, L., Stofflet, M., \& Martin, L. (2012). Exposure to partner, family, and community violence: Gang-affiliated Latina women and risk of unintended pregnancy. Journal of Urban Health, 89(1), 74-86. doi: http://dx.doi.org/10.1007/s11524-011-9631-0

Mitnick, D. M., Heyman, R. E., \& Slep, A. M. S. (2009). Changes in relationship satisfaction a cross the transition to parenthood: A meta-analysis. Journal of Family Psychology, 23(6), 848-852.

Ngai, F. W., \& Ngu, S. F. (2015). Predictors of maternal and paternal depressive symptoms at postpartum. Journal of Psychosomatic Research, 78(2), 156-161. doi: http://dx.doi.org/10.1016/j.jpsychores.2014.12.003 
National Association of Perinatal Social Workers. (2009). Standards for perinatal social workers working with patients experiencing post partum depression. Retrieved from http://www.napsw.org/code-ethics/

Orr, S. T., Reiter, J. P., James, S. A., \& Orr, M. A. (2012). Maternal health prior to pregnancy and preterm birth among urban, low income black women in Baltimore: The Baltimore Preterm Birth Study. Ethnicity \& Disease, 22, 85-89.

Parade, S. H., Blankson, A., Leerkes, E. M., Crockenberg, S. C., \& Faldowski, R. (2014). Close relationships predict curvilinear trajectories of maternal depressive symptoms over the transition to parenthood. Family Relations: An Interdisciplinary Journal of Applied Family Studies, 63(2), 206-218. doi: http://dx.doi.org/10.1111/fare.12065

Perinatal Mental Health Disorders Prevention and Treatment Act, § 15405 ILCS 95 (2008).

Postpartum Depression and Education Information, Stat. § 145.906 (2015).

Ramchandani, P., Stein, A., Evans, J., \& O’Connor, T. G., \& ALSPAC Study Team. (2005). Paternal depression in the post-partum period and child development: A prospective population study. Lancet, 365(9478), 2201-2205. doi: http://dx.doi.org/10.1016/S0140-6736(05)66778-5

Redshaw, M., \& Henderson, J. (2013). From antenatal to postnatal depression: Associated factors and mitigating influences. Journal of Women's Health, 22(6), 518525. doi: http://dx.doi.org/10.1089/jwh.2012.4152

Relating to Information Provided to Parents of Newborn Children, Health and Safety Code Ann., Title 2, § 161, 501, 502 (2005).

Relating to Perinatal Mental Health and Declaring an Emergency, Laws $75^{\text {th }}$ HS 2666 (2011).

Rhodes, A. M., \& Segre, L. S. (2013). Perinatal depression: A review of US legislation and law. Archives of Women's Mental Health, 16(4), 259-270. doi: http://dx.doi.org/10.1007/s00737-013-0359-6

Savitz, D. A., Stein, C. R., Ye, F., Kellerman, L., \& Silverman, M. (2011). The epidemiology of hospitalized postpartum depression in New York State, 1995-2004. Annals of Epidemiology, 21(6), 399-406. doi: http://dx.doi.org/10.1016/j.annepidem.2011.03.003

Schaar, G. L. (2012). Nurses facilitate change in medical practice: Unmasking postpartum depression. Journal of Obstetric, Gynecologic, and Neonatal Nursing, 41(Suppl 1), S7. doi: http://dx.doi.org/10.1111/j.1552-6909.2012.01359_1.x

Seehusen, D., Baldwin, L., Runkle, G., \& Clark, G. (2005). Are family physicians appropriately screening for postpartum depression? Journal of the American Board of Family Medicine, 18(2), 104-112. doi: http://dx.doi.org/10.3122/jabfm.18.2.104

Surkan, P. J., Peterson, K. E., Hughes, M. D., \& Gottlieb, B. R. (2006). The role of social networks and support in postpartum women's depression: A multiethnic urban 
sample. Maternal Child Health Journal, 10, 375-383.

doi: http://dx.doi.org/10.1007/s10995-005-0056-9

Uniform Maternal Screening Act, Code, Chapter 16, Public Health, Article 4E (2009).

U. S. Department of Health and Human Services, Office of the Surgeon General, Substance Abuse and Mental Health Services Administration. (1999). Mental health: Culture, race, ethnicity: Supplement to the report to the Surgeon General (Chapter 3: Mental health care for African Americans). Retrieved from http://mentalhealth.samhsa.gov/cre/ch3.asp

U. S. Department of Labor. (2012). Affordable Care Act. Retrieved from http://www.dol.gov/ebsa/healthreform/

Villegas, L., McKay, K., Dennis, C-L., \& Ross, L. (2011). Postpartum depression among rural women from developed and developing countries: A systematic review. The Journal of Rural Health, 27(3), 278-288. doi: http://dx.doi.org/10.1111/j.1748$\underline{0361.2010 .00339 . x}$

\section{Author note}

Address correspondence to: Robert H. Keefe, PhD, ACSW, LMSW, School of Social Work, University at Buffalo, SUNY, 685 Baldy Hall, Buffalo, NY 14260-1050.

Email: rhkeefe@buffalo.edu 